\title{
Genetics and hereditable IQ
}

\section{A new study of IQ among adopted siblings points to hereditable intelligence, but inconclusively. Geneticists (and others) should not however be fearful of a determination of the question.}

Is human intelligence genetically determined, environmentally conditioned or the product of both influences? Since the work of the late Cyril Burt was discredited some years ago, the ferocity seems to have gone out of the argument on this question that had been raging for close on half a century. The article that appears on p.620 of this issue, yet another piece of evidence that is by itself inconclusive, will in no sense reawaken that argument. It may however be an appropriate occasion for asking what would happen if ever the question were finally decided.

What T.W. Teasdale and David R. Owen have done is to attempt to discover in measurements made with genetic siblings brought up separately, usually as a consequence of adoption, the degree to which intelligence (as represented by measured IQ) is genetically determined. The study has been made possible by the accessibility of the adoption register in Denmark, and by the ready availability of data on educational attainment, IQ and height (as well as other physical attributes) for males who must register for military service at the age of eighteen. The availability of these data is in part a justification of the pleas that social scientists have been making in recent years that legislation to protect the privacy of individuals should not disallow access for the purposes of legitimate research.

The numbers involved in the study now reported are comparatively small. Five groups of sibling pairs (all male, since women do not register for military service) have been identified, of which two groups have been used, for practical purposes, as controls. One of these groups comprises genetically unrelated males adopted by the same parents and brought up together, the other a larger group of genetic brothers brought up by their natural parents. One essential element in the design of the study is the use of measurements of height (at the age of eighteen) as a kind of control variable. There is a wealth of earlier evidence to suggest that height is indeed heritable, so that height and IQ should behave similarly if, indeed, IQ is inherited.

The outcome of the study, so far as it goes, favours the hypothesis that intelligence is indeed genetically inherited. This, at least, is the outcome of a correlation between the IQs of adopted siblings reared apart. The standard calculation that this result may have arisen by chance yields a satisfactorily low value the odds are one in 200. But as with other studies of this kind, only some of the crucial questions that will arise in discussion of these data have at this stage been taken up. How comparable were the families into which the several groups of children were adopted? May there not be systematic differences between the families adopting related and unrelated siblings (other than the observation by Teasdale and Owen that parents adopting more than one child are likely to be well off)? One odd feature of the data now reported, however, is that the expected correlation in height among separately reared siblings does not unambiguously show up. The explanation may be the small size of the groups of adopted children, but until other explanations are excluded, the precise significance of this study cannot be certain.

None of this implies that the study has no immediate bearing on the question of whether intelligence is heritable. On the contrary, and at the very least, the study is an imaginative pointer to a source of data on heritability that has previously been almost entirely overlooked. One especially valuable feature of the Danish data is that the records of adoption and the measurements of IQ have been carried out for quite different purposes than that of the authors. Even if Burt's studies of genetic inheritance in identical twins had not been discredited by the suspicion that they may have been crudely fabricated, the fact that he was personally responsible for the measurement of IQ would by now have put his claims in doubt. One of the immediate consequences of what Teasdale and Owen have done will be to stimulate a search for other objectively gathered blocks of data that may throw light on the heritability of intelligence.

But why bother? One common assertion is that when a positive result (in favour of heritability) would be socially divisive, no good purpose can be served by answering the question. Such a response cannot however be regarded as a serious impediment to serious enquiry. If indeed IQ were shown unambiguously to be genetically determined, the result would be interesting in its own right and stimulating of other investigations. And even if it were the case that IQ is only a crude representation of what should properly be understood by intelligence, it would be even more remarkable that such an artefact, constructed from the ease with which individuals carry out artificial tasks, should be genetically determined than that unmeasured and per- haps unmeasurable intelligence should thus be determined.

Precisely what the practical consequences would be of a conclusive determination of the hereditability of IQ is another question. In the ancient row between the nature and nurture schools, it has commonly been assumed that the truth must be uncomfortable for one side or the other. That view should carry very little weight. For nobody pretends that if IQ is inherited, the effects can be as simple as in, for example, the inheritance of well-known physical disorders where a single gene may be responsible.

Everybody agrees that IQ, if inheritable at all, is determined by several genes, perhaps even indirectly. The result is that the IQ of the offspring of parents of known intelligence will be determined by some distribution spanning a range of measured values. Offspring of high-IQ parents will frequently have low IQs. Exactly the same kind of overlap is found in the distribution of IQ in racially different groups of children attending the same schools.

The consequence of these expectations of how measured IQ is likely to be distributed is that even when the question of heritability has been settled, few useful guides to social policy will have been provided. It will remain the case, for example, that societies that insist on educating the offspring of successful parents separately from others, on the twin assumptions that success denotes intelligence and that all offspring of intelligent parents are themselves intelligent, will imperfectly satisfy the needs of many of the children. It would be similarly profligate of human potential to suppose that, if IQ is heritable, schooling as such might be abolished on the grounds that native wit will make itself apparent.

In the whole field of social policy, exactly similar considerations apply. A determination of the question whether IQ is heritable would be largely irrelevant to policy, which is not to say that it would never be used as a means of justifying irrational prejudices. This is why studies such as those of Teasdale and Owen are warmly to be welcomed, why there is the strongest case for hoping that the issue will soon be clarified - and then for learning something of the mechanism by which such a fuzzy attribute of the central nervous system as intelligence may be, even in part, heritable. 